\title{
TRANSIÇÕES NO CICLO DE VIDA FAMILIAR: A PERSPECTIVA PATERNA FRENTE AO PROCESSO DE TRANSIÇÃO PARA A PARENTALIDADE
}

\author{
$*$ \\ Bruna Soares \\ Faculdades Integradas de Taquara - FACCAT - Brasil \\ Patrícia Manozzo Colossi \\ Faculdades Integradas de Taquara - FACCAT - Brasil
}

\begin{abstract}
Resumo
O processo de construção da paternidade é um fenômeno complexo, considerando, de modo especial, a transição da conjugalidade para a parentalidade. Nesse sentido, o presente estudo investigou a percepção dos pais acerca das mudanças ocorridas neste período em relação à conjugalidade e à construção da paternidade. Foi realizada uma investigação qualitativa de estudo de casos múltiplos, com três homens, residentes da Região Metropolitana de Porto Alegre, casados e em união estável e com filhos de até um ano e seis meses de vida. A análise dos dados foi baseada na perspectiva sistêmica da família. Os participantes apresentaram uma percepção positiva com relação a sua experiência nesta fase da vida, tendo conseguido lidar com as novas demandas e adoção dos papéis parentais que envolvem diferentes atribuições e responsabilidades. Contudo, revelaram-se também situações-problema na vida destes casais, que são resolvidas de modo que a qualidade do sistema conjugal e seu ajustamento sejam mantidos. Os resultados reforçam a importância da proximidade afetiva e da intimidade estabelecida pelo casal antes do nascimento do filho como um preditor para a manutenção do sistema nesse momento do ciclo de vida da família.
\end{abstract}

Palavras-chave: Parentalidade; Paternidade; Teoria sistêmica da família.

\section{Introdução}

A família é a primeira instituição que os indivíduos integram ao nascerem e é nela que se constituem como pessoas, já que ela é o primeiro laboratório de relações humanas que o sujeito conhece (OSORIO, 1996). Seguindo o modelo inter-relacional da família, os indivíduos a incorporam em sua personalidade, devido à influência que ela exerce sobre o funcionamento de seus membros (BLEGER, 1984).

Da mesma forma que a família influencia os membros que a compõem, é também influenciada por eles, em uma relação recursiva (VASCONCELOS, 2013), já que há um processo de influência mútua entre os envolvidos nas relações familiares. Os indivíduos influenciam a sua família, pois participam e atuam nas interações ativamente, estabelecendo uma dinâmica de funcionamento particular a esse sistema. 
O ciclo de vida individual dos membros da família provoca mudanças que se expressam no contexto familiar, uma vez que a família precisa se adaptar e se reorganizar para acolher a nova demanda do então, estágio de vida. Isto influi tanto no funcionamento do sistema familiar quanto em todos os seus membros (NICHOLS; SCHWARTZ, 2007). Logo, o ciclo vital não modifica apenas o indivíduo, mas também opera mudanças no sistema familiar que ele integra.

O casal, ao se tornar pais, precisa adaptar-se ao novo estágio de vida, aceitando um novo membro no sistema e ajustando-se como casal para lidar com as demandas de educação, tarefas domésticas e realinhamento da família para inclusão de novos papéis (CARTER; MCGOLDRICK, 1995). As mesmas autoras referem que a transição entre o estágio anterior e o posterior do ciclo de vida da família promove maior carga de estresse na organização familiar, gerando crises da família. Essas crises correspondem a um acúmulo de estresse oriundo da necessidade de adaptação ao novo estágio de desenvolvimento da família.

Independente da qualidade das crises, elas exigem flexibilidade e ajustamentos da família, em que negociações e realinhamento das relações devem ser realizados para que a família possa lidar de maneira funcional, garantindo sua continuidade e permitindo o crescimento de seus membros (ANDOLFI, 1996; CARTER; MCGOLDRICK, 1995). Esses estágios diferenciam-se pelos processos emocionais envolvidos em cada transição e pelas adaptações que a família precisa realizar, envolvendo arranjos e tarefas distintas. Assim, as transições de um estágio para outro podem gerar ansiedades e conflitos, pois elas afetam a estrutura e a homeostase familiar (CARTER; MCGOLDRICK, 1995; MINUCHIN, 1985; TOSIM, 2005).

Por conseguinte, entende-se que a mudança em um indivíduo na família levará a uma nova dinâmica do sistema, afetando a todos que participam dessa interação. Quando decorrentes do desenvolvimento e crescimento de seus membros, tornam-se, em alguma medida, previsíveis, mas exigem flexibilidade para manter a homeostase do sistema. Mesmo quando esperadas, não se descarta a possibilidade dos seus membros enfrentarem dificuldades, por vezes importantes, na adaptação a uma nova etapa. Dificuldades estas que podem ser superadas, mediante exercício de flexibilidade da família e adaptação às novas demandas.

Contudo, para muitas famílias a expectativa frente ao novo estágio e a necessidade de flexibilidade e adaptação pode ser um processo doloroso e gerador de sofrimento. Por certo, as transições consideradas definitivas, que promovem mudanças permanentes na família 
(como no caso de nascimentos e mortes), apresentam uma tendência a serem mais sentidas pela família (CARTER; MCGOLDRICK, 1995).

No caso do estágio de transição da conjugalidade para a parentalidade, destacam-se novas demandas e exigências como a atribuição de novos papéis, aprendizagem relacionadas às novas funções parentais, diminuição da satisfação conjugal, divisão de tarefas domésticas, educação, cuidado com o bebê e etc. Soma-se a isso a necessidade de organização do sistema conjugal para a entrada de um novo membro. Estudos acerca deste estágio do ciclo vital referem-se às questões maternas em diferentes contextos (DIAS; LOPES, 2009; FÉRESCARNEIRO, 2009; PICCININI; GOMES; DE NARDI; LOPES, 2008). Entretanto, identifica-se a escassez de estudos que deem voz aos parceiros masculinos do casal.

\section{Da conjugalidade à parentalidade: características da transição}

O nascimento de uma criança modifica a família de tal forma, que esta etapa do ciclo de vida familiar pode ser considerada aquela em que ocorrem as mais profundas mudanças no funcionamento da família (BRADT, 1995; MAGAGNIN et al., 2003; MINUCHIN, 1981). Esta transição é impactante devido às conjunturas que acompanham a chegada de um novo membro no sistema, antes caracterizado por uma díade. É a partir dessa transição que o sistema deixa de ser casal e é substituído pela condição de família (HINTZ; BAGINSKI, 2012).

O sistema que, até então, era composto por um único subsistema, o conjugal, formado por marido e mulher, precisa ajustar-se para criar espaço ao novo membro, sem haver prejuízos em sua relação conjugal, de forma que a continuidade da família possa ser mantida. O subsistema parental envolve uma nova ordem, que é estabelecida a partir do nascimento do primeiro filho, e que envolve novas tarefas, incluindo o cuidado e a socialização da criança (MUNICHIN, 1981). Essa adaptação, advinda da transição para a parentalidade, provoca o estabelecimento de novos padrões de interação, redefinindo a conjugalidade. $\mathrm{O}$ tempo, que antes era destinado a interesses pessoais e ao cônjuge, agora é voltado para o novo membro da família resultando na perda da exclusividade da relação conjugal (HINTZ; BAGINSKI, 2012; MAGAGNIN et al., 2003).

A intimidade desenvolvida durante o casamento sem filhos é entendida como aspecto preditor da capacidade dos cônjuges em responder às mudanças advindas da parentalidade, pois ela incentiva a continuidade do sistema. Os casais, quando bem organizados, evoluem nessa transição, tanto na condição de família, quanto na de cônjuges, tendo como resultado 
maior satisfação em sua relação. Contudo, o ajustamento dessa etapa também pode influenciar negativamente a intimidade do casal, quando gerada desigualdade na relação devido à dificuldade por parte de um dos cônjuges em adaptar-se quer como cônjuge quer como progenitor (BRADT, 1995; MAGAGNIN et al., 2003).

Um estudo longitudinal, realizado por Menezes e Lopes (2007), constatou que o envolvimento emocional do casal na fase anterior ao nascimento do bebê pode repercutir na manutenção da conjugalidade. A qualidade da relação afetiva dos casais mostrou-se relevante para a presença de uma crise superável nos sistemas familiar e conjugal. Mesmo com as mudanças da transição para a parentalidade, os casais que apresentavam maior envolvimento emocional na fase anterior ao nascimento do bebê experienciaram o aumento de companheirismo e união, além do sentimento de continuidade da relação conjugal. Ao contrário, aqueles que tinham um distanciamento emocional apresentaram maior dificuldade na manutenção da conjugalidade, estando mais suscetíveis à crise de maior intensidade. Assim, entende-se que a transição para a parentalidade pode promover a relação do casal, como também apresentar declínio no exercício da conjugalidade, sendo a qualidade da relação afetiva, anterior ao nascimento do bebê, um importante preditor para a manutenção de todo o sistema neste momento de crise.

Em sentido semelhante, os resultados de um estudo realizado por Hernandez e Hutz (2009) acerca do ajustamento conjugal e emocional em gestantes primíparas no período de transição para a parentalidade, nos períodos pré e pós-natal, constataram a ocorrência do declínio no ajustamento conjugal após o nascimento do bebê. As mulheres investigadas relataram a experiência de considerável turbulência nas relações, além de perceberem transformações e mudanças na relação do casal. Os autores inferiram que a tendência deste declínio pode estar associada à aprendizagem de novos papéis, desenvolvimento de novos relacionamentos e reorganização daqueles já estabelecidos.

Neste sentido, as repercussões que ocorrem na relação do casal, possivelmente, advêm das novas funções surgidas com o processo intenso e constante da parentalidade (HINTZ; BAGINSKI, 2012). Essas novas atribuições demarcam a mudança do sistema de casal para família, e para estas autoras, esta é uma das dificuldades que os novos pais enfrentam, por ser percebida como definitiva para o mundo adulto. A entrada do filho no sistema familiar traz consigo novas responsabilidades, exigindo uma nova reestruturação dos indivíduos, que nem sempre estão preparados para tal transformação.

Uma organização importante no desenvolvimento da parentalidade é a atribuição dos papeis parentais, a partir dos quais os cônjuges irão reorganizar sua relação conjugal abrindo 
espaço para o aprendizado e o exercício da paternidade e maternidade. A adoção destes papeis envolve novos comportamentos que são percebidos de maneiras distintas entre os gêneros, devido às atribuições sociais que eles carregam (MARTINS; ABREU; FIGUEIREDO, 2014). Os mesmos autores destacam as mudanças no modelo patriarcal da paternidade, transformando a figura do pai como associada a de provedor da família, passando a ter maior envolvimento emocional e cuidado com os filhos. Entretanto, reconhecem que muitos casais ainda tendem a adotar uma postura tradicional em relação à divisão das tarefas após o nascimento de um filho. É comum que muitos casais ainda se organizem de acordo com referenciais tradicionais, nos quais as mães assumem o principal papel de cuidado, disponíveis integralmente à criança, enquanto o pai assume um papel secundário, de provedor e apoio, estando mais ausente dos cuidados infantis.

As mudanças ocorridas na sociedade ocidental têm modificado o modelo de família centrado na figura masculina, ampliando a participação e o envolvimento da mulher no mundo social e do trabalho e, como consequência disso, também o comportamento e as atitudes dos homens em relação ao cuidado dos filhos têm se modificado. No entanto, as mulheres ainda são as principais responsáveis por este cuidado e pelo trabalho doméstico. Isso, por vezes, acarreta a sobrecarga feminina e maior insatisfação com o relacionamento conjugal após o nascimento dos filhos (CARTER; MCGOLDRICK, 1995; MARTINS et al., 2014).

Entretanto, quando o homem se diferencia deste modelo patriarcal, envolvendo-se ativamente com o seu papel parental, permite a construção de sua paternidade, tornando-se mais disponível para a demonstração de afeto e cuidado do filho. Além disso, a sua atuação frente às tarefas domésticas, que antes poderiam recair somente sobre a esposa; com o nascimento do bebê, pode tornar-se necessária, visto que agora o envolvimento com o bebê limita o tempo da mãe, diminuindo sua disponibilidade e disposição para essas tarefas. Essas atividades, quando desempenhadas em conjunto, refletem positivamente na relação do casal (MENEZES; LOPES, 2007).

Neste sentido, destacam-se diferentes fatores capazes de influenciar na intensidade desta crise e possibilidade de superação. O exercício da paternidade, e o modo como ele é desempenhado, mostram-se como aspectos relevantes que contribuem para que o casal disponha de recursos socioemocionais para juntos, encontrarem alternativas de adaptação às demandas advindas do novo momento de vida da família. 


\section{A paternidade na contemporaneidade}

O exercício da paternidade tem apresentado transformações ao longo do tempo, de forma que o significado deste papel na família tem mudado a perspectiva do que é "ser pai". Essas modificações se devem a diferentes fatores como as mudanças socioeconômicas e culturais, que afetam não só o modo de vida dos indivíduos, como também a maneira como interagem no meio em que estão inseridos. Essas mudanças repercutem no funcionamento familiar, na rotina de homens e mulheres, implicando também nos papéis sociais por eles desempenhados (ARRUDA; LIMA, 2013).

$\mathrm{Na}$ sociedade ocidental do início do século XX, a família era caracterizada pelo modelo hierárquico, no qual o poder e o saber pertenciam ao homem, provedor da família. A mulher era responsável pelo cuidado dos filhos e serviço doméstico, estando abaixo do homem na hierarquia familiar. A relação entre pais e filhos era distante, os assuntos familiares eram discutidos sem a presença desses últimos e a manifestação do afeto não acontecia por meio da aproximação física. Os papéis parentais eram rigidamente demarcados, sem interferência no exercício do outro. Esse modelo caracteriza o modo de vida patriarcal que, ao longo da história tem aberto espaço para um modelo contemporâneo em que pesam relações mais igualitárias, modificando os valores e os modos de vida individuais e familiares (ARRUDA; LIMA, 2013; HINTZ, 2001; NEGREIROS; FÉRES-CARNEIRO, 2004).

As mudanças sociais ocorridas ao longo do tempo promoveram a saída da mulher para o mercado de trabalho e sua crescente autonomia. Por outro lado, a transformação do papel da mulher na conjugalidade, na família e na sociedade, contribuíram para as referidas mudanças sociais, recursivamente. A estrutura hierarquizada começou a dar vazão a padrões relacionais mais igualitários, influenciando desta forma a dinâmica da família. As decisões, tanto com relação aos filhos, como em questões de administração do lar e financeiras, passaram a ser, gradativamente, compartilhadas. Pais e filhos têm modificado suas relações, sendo o diálogo e a expressão de afeto uma característica possível no funcionamento de famílias atuais. Assim, há uma reformulação nos papéis masculinos e femininos, já que as questões relacionadas ao comportamento dos gêneros passaram a ter maior flexibilidade (HINTZ, 2001; NEGREIROS; FÉRES-CARNEIRO, 2004).

Neste sentido, passamos a ter dois modelos coexistentes de famílias: um tradicional e um igualitário (NEGREIROS; FÉRES-CARNEIRO, 2004). Contudo, não se pode pensar na substituição de um modelo pelo outro. As mesmas autoras denominam de "modelo antigo" e "modelo novo", sendo que na atualidade, os dois modelos convivem conflituosamente na 
subjetividade dos indivíduos, sem que um substitua o outro. Costumes e valores ligados às raízes tradicionais se encontram presentes no "modelo novo", podendo gerar insatisfações e dificuldades nas relações conjugais pelas percepções dúbias que esses atravessamentos causam. Os pais, de modo específico, têm experienciado dificuldades no exercício das práticas parentais, por acreditarem que a mãe faz melhor que eles, o que é um engano motivado pelo modelo antigo de ser pai e mãe (ARRUDA; LIMA, 2013).

Ao compartilhar as atribuições consideradas masculinas com as mulheres, os homens agora são convidados a entrar em um novo universo, participando da rotina doméstica e envolvendo-se efetiva e afetivamente na criação dos filhos (STAUDT; WAGNER, 2008), já que a atuação social e profissional feminina tem se tornado cada vez mais ativa. No entanto, estudos referem que em muitos casos, as mulheres passaram a acumular funções, pois a sua inserção no universo masculino aconteceu com disparidade, considerando que as tarefas domésticas e os cuidados com os filhos por parte dos homens não acontecem na mesma proporção (ANDOLFI, 1996; ARRUDA; LIMA, 2013; CARTER; MCGOLDRICK, 1995; MARTINS et al., 2014; STAUDT; WAGNER, 2008).

Entretanto, existe uma contradição entre as exigências de maior envolvimento dos pais nos cuidados aos filhos e suas reais possibilidades. Se por um lado, a sociedade exige um homem mais participativo no desenvolvimento de seus filhos, ainda mantém valores sociais arraigados em um modelo tradicional. Pesam ainda, condições trabalhistas desiguais em que a licença maternidade, por exemplo, é de quatro a seis meses, e o tempo que o pai pode ficar com o filho após o nascimento é de cinco dias corridos (STAUDT; WAGNER, 2008).

Além de questões sociais, o espaço oferecido ao pai para a construção de sua paternidade parece constituir-se outro aspecto que interfere no exercício da paternidade. A participação dos pais na vida dos filhos, por vezes, é definida de acordo com o desejo da mãe (ARRUDA; LIMA, 2013). Se o cuidado dos filhos era exclusivamente feminino, e aí estava o poder significativo da mulher; o controle que algumas delas exercem sobre essa atividade, por vezes, dificulta a participação masculina. É possível que esteja associado ao medo de perder o poder feminino, ocasionando o afastamento físico e emocional do pai na primeira fase de vida do bebê (ARRUDA; LIMA, 2013).

Deste modo, questiona-se a respeito de como ficam os pais diante das transformações familiares e sociais contemporâneas. A transição da conjugalidade para a parentalidade pode constituir-se em uma fase em que faltem parâmetros definitórios contemporâneos de orientação acerca do papel paterno. Gomes e Resende (2004), buscando elucidar como o pai transita entre valores tradicionais e novos, identificaram que os pais parecem abertos às novas 
exigências familiares, fazendo-se mais presentes e envolvendo-se emocionalmente com os filhos no cotidiano da família. Os pais investigados diferenciam-se do modelo tradicional vivido em sua infância e percebem que é possível exercer a paternidade de maneira oposta à experienciada (GOMES; RESENDE, 2004).

Na mesma perspectiva, o estudo de Sutter e Bucher-Maluscheke (2008) teve o objetivo de compreender o sentido dado à paternidade e à masculinidade por homens que vivenciam o cuidado cotidiano com os filhos. Os resultados apontaram que o sentido da paternidade para os homens investigados é baseado no amor, intensidade emotiva, sensibilidade e prazer na relação com os filhos. Mesmo com a experiência de um passado patriarcal, esses pais foram capazes de acolher, cuidar e amar. Ao envolverem-se emocionalmente com seus filhos, eles distanciaram-se do estereótipo masculino, marcado pela capacidade de proteção e provisão da família. Segundo as mesmas autoras, se os homens possuem a capacidade de cuidar e de amar, estas características também devem ser entendidas como atributos masculinos.

A partir do exposto, questiona-se como os pais da contemporaneidade vivenciam esta experiência. Destaca-se, com isso, a relevância de compreender a percepção dos pais diante desta fase do ciclo vital, bem como o modo como se constituem em seu papel paterno. Neste sentido, o presente estudo teve o objetivo de compreender a percepção paterna acerca das transformações ocorridas nesta fase de desenvolvimento do ciclo vital familiar.

\section{Método}

\subsection{Delineamento}

Tratou-se de um estudo qualitativo exploratório, de estudo de casos múltiplos (YIN, 2015), que buscou conhecer em profundidade a percepção paterna frente ao processo de transição da conjugalidade para a parentalidade. Além disso, buscou identificar como os pais percebem a construção de sua paternidade em suas diferentes dimensões.

\subsection{Participantes}

Participaram deste estudo três homens, pais primíparos, casados e em união estável há mais de quatro anos, selecionados por conveniência em uma escola de educação infantil em uma cidade da Região Metropolitana de Porto Alegre. Foi critério de inclusão os pais terem filhos com idade até um ano e seis meses de vida. 


\subsection{Instrumentos}

Questionário de dados sóciodemográficos: utilizado para coleta de informações acerca da ordem social, educacional e financeira, focalizando aquelas de cunho familiar.

Entrevista Semiestruturada: elaborada para este estudo, com o propósito de conhecer a percepção dos participantes sobre a transição para a parentalidade, abrangendo seus sentimentos para com a esposa e para com o filho, investigando aspectos da conjugalidade, parentalidade e entendimento acerca da construção da paternidade.

Golombok Rust Inventory of Marital State (GRIMS): utilizado para avaliar qualitativamente a qualidade do relacionamento conjugal dos participantes. Composto por 28 itens, os sujeitos devem pontuar acerca da satisfação, comunicação, interesses compartilhados, confiança e respeito; considerados importantes em um bom casamento.

Escala de Ajustamento Diádico (Dyadic Ajustment Scale- DAS, Spanier, 1976): também utilizada com o objetivo de avaliar o ajustamento conjugal. Composta de 32 itens, apresentada em escala Likert de cinco, seis e sete pontos, busca identificar: consenso satisfação e coesão diádicos e expressão de afeto. A escala é pontuada a partir do escore total do instrumento, a fim de qualificar o relacionamento conjugal. Neste sentido, considera-se que o casal apresenta uma relação conjugal de ajustamento ou não.

\subsection{Procedimentos éticos, de coleta e análise dos dados}

Após submissão e aprovação do Comitê de Ética em Pesquisa de uma Instituição de Ensino (Protocolo ${ }^{\circ}$ 907/2015), inicialmente visitou-se uma escola de educação infantil de uma cidade da Região Metropolitana de Porto Alegre, para recrutamento dos participantes. $\mathrm{O}$ projeto foi apresentado à direção da escola que selecionou os pais de uma turma que atendia aos critérios de participação do presente estudo.

A fim de cumprir as exigências contidas nas resoluções 466/2012 do CNS e 016/2000 do CFP acerca das pesquisas com seres humanos, os pais foram comunicados acerca do presente estudo e, aqueles que manifestaram interesse em participar, tiveram seus contatos telefônicos divulgados à pesquisadora. As entrevistas foram marcadas, conforme preferência dos participantes e realizadas em seus domicílios. Depois de esclarecer o estudo, os participantes assinaram um Termo de Consentimento Livre e Esclarecido(TCLE) e deu-se início à coleta dos dados. O questionário de dados sóciodemográficos, as escalas GRIMS e DAS e realizadas as entrevistas com duração aproximada de uma hora. 
A análise dos dados foi qualitativa, baseada em estudo de casos múltiplos (YIN,2015), à luz da perspectiva sistêmica da família. Cada caso foi analisado individualmente, a fim de compreendê-lo em profundidade e, após a análise individual, as informações foram cruzadas, buscando identificar convergências e divergências.

\section{Resultados e Discussão}

\section{CASO 1 - Pedro ${ }^{1}$}

Pedro (40 anos) é casado há quatro anos. Possui formação superior e ele e a esposa trabalham fora de casa. À época da coleta de dados, seu filho, Kauan, tinha um ano e cinco meses. Pedro morou fora do país e, ao retornar, tinha o desejo de constituir família. Essa experiência parece influenciar os planos futuros que tem para o filho. Pedro pretende sair do país novamente, agora com a família. Conta que quando conheceu a esposa soube que seria um relacionamento diferente, acreditando que, com ela, constituiria sua família. Ele refere que a decisão de ter um filho foi conjunta, e após dois anos e meio de relacionamento, optaram por "não postergar, não deixar para depois" (sic). O participante entende que ser pai é algo relevante, sendo "uma missão importante que a gente tem que ter" (sic) e sente-se realizado por exercer esse papel. Pedro declara que antes do nascimento de Kauan o casal "sempre se deu bem” (sic), tinham uma boa comunicação e percebe que essas características se mantiveram após o nascimento do filho. Relata que ele e a esposa sempre foram muito unidos, e que a chegada do bebê fez com que se sentisse ainda mais próximo à esposa.

A realidade de Pedro reforça os achados científicos que revelam que casais que apresentam maior qualidade conjugal, com presença de intimidade e envolvimento emocional significativo antes do nascimento do bebê, tendem a responder positivamente às mudanças advindas da parentalidade. Além de evoluírem para a condição de família, há um amadurecimento do relacionamento conjugal, com maior satisfação da relação, o que contribui para a continuidade do sistema e para a manutenção da relação com o cônjuge (BRADT, 1995; MAGAGNIN et al., 2003; MENEZES; LOPES, 2007).

Resultados obtidos com as escalas de avaliação conjugal (GRIMS e DAS) revelam a presença de eventuais situações-problema na vida do casal resolvidas de modo a manter a qualidade da relação e o ajustamento conjugal. Os resultados revelam que Pedro e Beatriz são capazes de lançar mão de recursos emocionais para manter a funcionalidade da relação,

\footnotetext{
${ }^{1}$ Os nomes foram alterados para preservação do anonimato dos participantes.
} 
mesmo com a presença de novas demandas familiares. Entende-se que esses resultados podem estar relacionados com as mudanças e as novas tarefas que chegam com a parentalidade. $\mathrm{O}$ sistema, antes composto por uma díade, precisa ajustar-se para a chegada do novo membro e acolher as demandas dessa etapa. Essa adaptação provoca mudanças nos indivíduos que precisam redefinir sua relação conjugal em um momento crítico do desenvolvimento (HINTZ; BAGINSKI, 2012; MAGAGNIN et al., 2003).

Pedro percebe a dinâmica conjugal estabelecida como um ganho após a entrada de Kauan no sistema familiar, mas também avalia perdas no relacionamento conjugal. Relata a perda de contato com a esposa, pois atualmente as atividades são voltadas para a família, e não mais para o casal. Manifesta não ser o ideal, mas que é difícil priorizar a relação conjugal nesse momento. Refere que antes do nascimento ele e a esposa planejavam como seria a vida, cuidados básicos e o dia-a-dia com o filho, mas depois, nem tudo é como o planejado. Muitas coisas mudaram, foram se adequando à realidade e às demandas do cotidiano.

Ele acredita que o casal divide de modo equilibrado as tarefas parentais, já que ele leva e busca Kauan na escola; troca fralda e alimenta o filho até que a esposa chegue. Também dá banho e administra medicações. Já a alimentação é a cargo da esposa, assim como preparar o filho e seus pertences para a escola. Também é ela quem assume os cuidados à hora de dormir, já que Kauan ainda mama no peito. Quanto às tarefas domésticas, Pedro percebe equilíbrio, pois ele se responsabiliza pelas roupas e ela é responsável pela alimentação e limpeza da casa. Pedro se empenha para manter as coisas em ordem, contribuindo com a organização da casa. Estudos referem que mesmo os homens adotando uma ação mais igualitária nas tarefas domésticas, há uma distância entre o discurso e a prática, havendo um comportamento não compatível com as reais demandas e sua divisão equilibrada, sendo eles coadjuvantes nas responsabilidades domésticas de suas esposas (JABLONSKI, 2010). No entanto, o envolvimento relatado por Pedro, tanto nas tarefas domésticas quanto parentais, pode refletir positivamente na relação do casal visto que, após o nascimento, as demandas ampliam-se e o tempo da mãe fica limitado dado o envolvimento com os cuidados do bebê. Então, mesmo que não haja uma simetria na divisão de tarefas, o envolvimento relatado por Pedro parece repercutir no ajustamento e na qualidade da relação do casal, além disso o envolvimento dos homens em seu papel parental possibilita a construção de uma paternidade mais disponível para a demonstração de afeto e cuidado com seu filho (MENEZES; LOPES, 2007) e possivelmente há repercussões positivas na relação que ele estabelece com Kauan.

Esse dado pode ser confirmado na experiência de Pedro, que relatou sentir-se pai não em função do nascimento de Kauan, em si, mas à medida que convivia com seu filho, 
pegando-o no colo, trocando a fralda, cuidando e interagindo com ele. Refere que os momentos de interação com seu filho são constantes, "desde o momento em que ele acorda até a hora de dormir. Claro que com intervalos de trabalho, né, porque eu levanto de manhã, levo para escola e quando busco, fico com ele, brinco, coloco na cama, sacudo, afago, deito, brinco com ele, é bem legal” (sic). Esses momentos de interação são percebidos pelo pai como prazerosos. Ele destaca que se sente feliz e satisfeito quando está com o filho em cada conquista e aprendizagem dele. Relata perceber que se envolve emocionalmente com o filho de maneira mais transparente, se comparado ao tempo em que ele foi criança, demonstrando afeto a partir de gestos, palavras e brincadeiras. Considera ser diferente o modo como foi educado e os cuidados paternos proporcionados a Kauan. Acredita que o próprio pai tenha feito o melhor, mas que a sua realidade é diferente, contando com mais informações a respeito do desenvolvimento infantil, acreditando que esteja fazendo ainda melhor para o seu filho.

A disponibilidade de Pedro ao filho revela as transformações que o exercício da paternidade tem apresentado ao longo do tempo, mudando a perspectiva do "ser pai" (ARRUDA; LIMA, 2013). Pode-se referir que Pedro foi educado em um modelo tradicional, mas que as mudanças e as demandas da contemporaneidade o fazem transitar para uma paternidade mais aberta e participativa no que diz respeito aos sentimentos e aos cuidados destinados ao seu filho, diferenciando-se do modelo tradicional vivido em sua infância (GOMES; RESENDE, 2004).

Com relação às demandas profissionais e o impacto na sua relação com o filho, Pedro percebe a necessidade de estar fora do lar para trabalhar como algo natural, tanto para os pais quanto para as mães, visto que essa é uma necessidade emergente da sociedade ocidental. Parece satisfeito quando explica o cuidado prestado ao filho, manifestando não ter preocupações quanto ao bem-estar de Kauan quando ele está na escola. Entretanto, lamenta por não passar mais tempo com seu filho, para poder desfrutar e acompanhar o seu crescimento. Quanto aos fatores que o impedem de exercer a paternidade, não identifica fator emocional que o impeça, mas relata que o fator financeiro, por vezes, acaba impedindo que alguns de seus desejos ou planos que tinha para seu filho, antes mesmo dele nascer, não seja concretizado, como fazer aula de natação juntos por exemplo; expressando, mais uma vez, o desejo de estar próximo do filho.

$\mathrm{O}$ caso apresentado reflete as mudanças no exercício da paternidade devido às demandas, cada vez mais em pauta na contemporaneidade. A entrada das mulheres no mercado de trabalho corrobora para a mudança de paradigma, já que os homens passam a compartilhar as atribuições consideradas masculinas com as mulheres e são, em contrapartida, 
convidados a vivenciar o universo considerado feminino, participando da rotina doméstica e envolver-se mais efetiva e afetivamente na criação dos filhos (STAUDT; WAGNER, 2008).

\section{CASO 2 - Guilherme}

Guilherme (33 anos) está casado há 11 anos. Ele tem ensino médio e Gabriela, sua esposa, ensino superior; ambos trabalham fora. Victor, filho do casal, à época da coleta de dados estava com um ano e quatro meses de vida. Guilherme relata que a decisão de ter um filho foi partilhada, após oito anos de relacionamento, sendo um desejo desde que casaram. Quando questionado a respeito do significado de ser pai, ainda que tenha referido a dificuldade em expressar-se com palavras, descreve sentir "uma felicidade enorme" (sic). Relata que essa experiência lhe desperta bons sentimentos e lhe remete a lembranças do passado com seu pai.

Com relação às mudanças relacionadas à chegada de Victor, Guilherme destaca que poucos foram os ajustes necessários, por considerar que ele e Gabriela desejavam a chegada do filho. Declara perceber poucas mudanças na rotina, como os programas feitos pelo casal antes da chegada de Victor e agora são mais voltados para atividades familiares. Também refere que o casal está voltado para o cuidado do filho, havendo uma mudança em sua comunicação, visto que o filho já entende o que casal conversa. Refere a necessidade de adaptação de espaços da casa para garantir a segurança do filho.

Relata que a relação do casal antes no nascimento de Victor "era boa, claro de vez em quando tinha umas situações, mas nada sério. É, um bom relacionamento, tranquilo" (sic) e acredita que o casal possui o mesmo funcionamento de quando não tinham filho, não identificando muitas mudanças na relação conjugal após o nascimento de Victor. No entanto, sabe-se que a entrada de um membro no sistema familiar envolve novas tarefas, como o cuidado básico e a socialização da criança (MINUCHIN, 1981) e por essa razão, a transição para a parentalidade envolve, entre outros fatores, a adaptação dos indivíduos para assumir essas novas demandas e, ainda, novos papeis. Como casal, o tempo dos indivíduos é voltado para seus próprios interesses e ao cônjuge. Com a chegada do bebê, a dinâmica de funcionamento tende a mudar, acarretando novos padrões de interação, perda da exclusividade da relação conjugal, resultado a redefinição da conjugalidade do casal (HINTZ; BAGINSKI, 2012; MAGAGNIN et al.).

Guilherme acredita que as atividades parentais são divididas e percebe-se atuante nos cuidados destinados ao Victor. Contudo, em função da rotina profissional da esposa, que 
trabalha em dias alternados, ele realiza os afazeres domésticos quando ela não está; mas refere que as tarefas da casa são responsabilidade dela, revelando uma percepção nem sempre adequada da realidade. É possível que seja um aspecto da desejabilidade social frente à pesquisadora. Ao que parece, há um desequilíbrio na divisão das tarefas tanto parentais quanto domésticas. É possível que a percepção de Guilherme esteja associada ao relato de ter havido "poucas mudanças" na dinâmica do casal após a chegada de Victor. Mesmo que exista uma atuação de Guilherme em relação aos cuidados de Victor, seu comportamento demonstra a distinção social ainda existente na adoção de papeis parentais, guiados por suas atribuições sociais. Os pais ainda se organizam de acordo com referenciais tradicionais, nos quais as mães assumem o principal papel de cuidado, estando disponíveis integralmente à criança, enquanto o pai assume um papel secundário, de provedor e apoio, estando mais ausente nos cuidados infantis (MARTINS et al., 2014). Portanto, existe um movimento na prática parental no que diz respeito ao envolvimento emocional e ao apoio prestado à Gabriela nos cuidados de Victor, mas o predomínio das atribuições parentais e domésticas, são, ainda, de responsabilidades do gênero feminino.

Guilherme relata que passou a sentir-se pai a partir de sua participação no parto do filho, corroborando resultados de estudos que referem que, para muitos pais, o auge do sentimento de "ser pai" é realmente alcançado com o nascimento do filho, em que o bebê sai do imaginário e recebe uma representação concreta, tendo o pai a possibilidade de tocá-lo, senti-lo, pegá-lo no colo. Essas possibilidades de concretização da paternidade geram uma forte emoção e remetem às responsabilidades que envolvem a geração de um filho (FREITAS; COELHO; SILVA, 2007).

Os momentos de interação de Guilherme e Victor acontecem na rotina da família, em que o pai leva o filho para a escola, intercalando os dias em que vai sozinho e os dias em que vai acompanhado de Gabriela. Outro momento de interação é quando busca Victor na escola e aguardam a chegada de Gabriela do trabalho, nos dias em que ela não está em casa. Relata que geralmente sua irmã o acompanha para ficar com Victor em casa até o momento em que busca sua esposa no trabalho. Depois da chegada de Gabriela eles dão o banho e ele é quem coloca-o para dormir, já que Victor está ficando grande e pesado. Conta que nos finais de semana, a família vai para o sítio e que são momentos especiais em que o casal passeia com o filho, o que lhe deixa muito feliz.

Quanto às demandas profissionais, Guilherme relata que o trabalho lhe exige muito, às vezes 24hs. Percebe que isso atrapalha o exercício da paternidade, visto que em alguns períodos fica "ausente" por até quinze dias, passando em casa, apenas para tomar banho e 
dormir. Por essa razão, acredita que "interfere, atrapalha sim, com certeza, mas fazer o que? Precisamos trabalhar, né” (sic). Guilherme acredita que as questões financeiras são a maior diferença entre a sua paternidade daquela exercida pelo seu pai e seu avô, pois pode ofertar mais bens materiais para o filho, não identificando diferença na expressão do afeto no que diz respeito as relações estabelecidas entre pai e filho. Observou-se a partir desse relato, que sua percepção quanto à expressão de afeto seja semelhante ao das demais gerações devido a sua demonstração de afeto ser a mesma que os homens de sua família tinham para com os seus filhos. Além disso, percebeu-se que Guilherme se organiza de acordo com os referenciais tradicionais de paternidade, no qual o pai assume um papel secundário na disposição ao cuidado da criança, sendo que suas atribuições são voltadas ao apoio a sua esposa e ao sustento da família (MARTINS et al., 2014).

\section{CASO 3 - Gabriel}

Gabriel (26 anos) vive em união estável há seis anos com Vitória (26). Cursou o ensino médio e Vitória cursou o ensino superior. Ambos trabalham fora sendo que Gabriel possui dois empregos. O casal tem um filho, Santiago, que no período da coleta de dados estava com um ano e quatro meses de idade. Gabriel relata que houve um planejamento para a chegada de Santiago na família, e que o casal optou por concluir a construção da casa e realizar um plano de saúde para depois ter o primeiro filho. Refere também que "se a gente fosse começar a botar empecilho, ah, não é o momento ainda, não é o momento ainda, a gente nunca ia achar que ia tá preparado para esse momento” (sic). Diante disso, o casal decidiu ter o filho logo após o término dos ajustes finais necessários em sua casa. No período em que tomaram a decisão estavam casados há três anos. Relata que as famílias de origem brincavam com relação a chegada de um bebê, mas ele não percebia como uma pressão para ter um neto por partes das duas famílias.

Gabriel sente dificuldade em expressar-se quando questionado a respeito do significado de ser pai e relata que perdeu seu pai quando tinha seis anos de idade e que esse fato veio à tona quando soube que seria pai de um menino. Relata que teve recordações do tempo em que seu pai ainda era vivo e destaca que se sente alegre por ter um filho. Refere ainda que foi difícil aceitar a perda de seu pai, dado o motivo da morte (suicídio), o que lhe deixou "marcas" (sic). Então, quando soube que teria um filho pensou que deveria ser" $o$ melhor pai possível para procurar ser o melhor pai para ele, como um que eu não tive. Não 
que tenha sido ruim; o meu padrasto, só tenho a agradecer a ele. Quero dar ao meu filho aquilo que eu não tive, assim, do meu pai” (sic).

Gabriel aponta que após o nascimento de Santiago percebe mudanças significativas na vida do casal, visto que antes do nascimento de seu filho o compromisso que ele tinha era apenas com a esposa. Não havia maiores preocupações quanto ao planejamento em sair para uma viagem ou uma festa, por exemplo. Atualmente percebe o casal limitado em realizar alguns programas devido às responsabilidades de ter um filho pequeno e demandas próprias. Com isso, Gabriel revela o quanto o casal parece ter se ajustado à condição de família, já que parecem estar adaptando suas atividades de acordo com as demandas do bebê. Além disso, percebe-se a perda da exclusividade da relação conjugal, em que o tempo antes era destinado a interesses pessoais e conjugais, passa a voltar-se para o bebê e suas necessidades. Essas adaptações se devem à transição para a parentalidade e acabam provocando mudanças nos indivíduos, que passam a estabelecer novos padrões de interação (HINTZ; BAGINSKI, 2012; MAGAGNIN et al., 2003).

Gabriel percebe que a comunicação com Vitória acontece de modo semelhante à quando não tinham Santiago, pois costumam, diante de algum conflito, sentar e conversar e buscar resolver. Entretanto, ressalta que se percebe inseguro com relação à saúde do filho. Nas situações em que ele ficou doente aconteceu de ambos os pais ficarem nervosos e passaram a “conversar, assim, 'meio estranho' um com o outro naquele momento ali. Depois passa aquilo e a gente conversa, pede desculpa pelo que aconteceu” (sic). Essas repercussões que ocorrem na relação do casal, possivelmente, advêm das novas funções surgidas com o processo intenso e constante que é a parentalidade. As novas atribuições demarcam a mudança do sistema de casal para família, e a entrada do filho no sistema familiar traz consigo novas responsabilidades, exigindo uma nova reestruturação dos indivíduos (HINTZ; BAGINSKI, 2012).

Quanto às tarefas parentais, Gabriel relata que tem se percebido mais envolvido atualmente nas atividades de cuidado com Santiago, pois "quando ele era pequeninho, assim, eu nunca dei banho nele, eu tinha medo de machucar"(sic). No entanto, atualmente ele auxilia no banho sempre que possível, leva Santiago à escola acompanhado de Vitória e, por vezes, busca o filho sozinho. A alimentação e troca de fraldas ficam por conta de Vitória, mas ele auxilia nesses afazeres quando ela está envolvida em outras atividades. Mesmo que Gabriel participe dessas tarefas, ele declara que percebe a esposa com maiores responsabilidades quanto ao cuidado de Santiago. Observa-se que nesse caso o exercício da paternidade está relacionado com o modelo tradicional no qual o pai assume o papel de 
provedor, auxiliando a mãe nas demandas do bebê quando necessário, disponibilizando um apoio à esposa nas tarefas parentais, mas não tomando essa responsabilidade para si (MARTINS et al., 2014). Também foi possível observar que os costumes e valores ligados às raízes tradicionais do "ser pai" levam Gabriel a experienciar dificuldade no exercício das tarefas parentais. Essa crença leva os homens a acreditar que a mãe desempenha as tarefas parentais melhor do que eles, acreditando que elas desempenham essa tarefa com maior eficácia (ARRUDA; LIMA, (2013).

Com relação às tarefas domésticas, Gabriel refere que atualmente o casal possui combinações, já que Vitória cuida da casa e ele cuida da garagem e do pátio. Isso se estabeleceu devido sua rotina atual, pois ele tem trabalhado em dois empregos, assim passa menos tempo em casa. Destaca que essas tarefas já foram divididas de forma equilibrada, quando Vitória estudava era ele quem cuidava da casa, fazia a janta e o almoço, já que sua carga horária era menor. Acredita que por essa razão Vitória esteja mais envolvida, não só com as tarefas domésticas, mas com os cuidados prestados a Santiago também. Entretanto, Jablonski (2010) aponta que homens e mulheres tendem a adotar um comportamento tradicional no que diz respeito ao cumprimento das tarefas parentais e domésticas após tornarem-se pais e mães, mesmo quando o casal tinha uma divisão igualitária num período anterior ao nascimento dos filhos. Segundo o mesmo autor, essa adoção de papeis se dá independentemente do nível educacional e profissional das mulheres e das divisões que existiam anteriormente.

Gabriel descreve que passou a sentir-se pai já nas primeiras semanas de gestação do filho. Relata que ao saber da gravidez da esposa sentiu uma grande emoção e que o som do coração de Santiago batendo, na primeira ecografia, lhe deixou extasiado. Porém, destaca que se sentiu realizado quando pegou Santiago pela primeira vez no colo, pois após o nascimento "o sonho se tornou realidade, porque até então tu vê se mexer, tu escuta os barulhinho, batimento do coração[...] só que tu não tá... tu não tá vendo” (sic). Freitas, Coelho e Silva (2007) destacam que o sentimento de ser pai emerge em diferentes momentos, até mesmo na gestação. É possível que para aqueles homens que percebem a existência desse sentimento antes do nascimento do bebê haja, além de uma proximidade física com a gestante, um envolvimento afetivo e a gestação como um projeto construído pelo casal. Todavia, os autores destacam que esse sentimento que se inicia na gestação, atinge sua máxima com o nascimento do filho, em que há a concretização do imaginário na experiência real.

Quanto aos momentos de interação com Santiago, Gabriel refere que se sente feliz e realizado, pois percebe o filho sorridente, parecendo feliz também. Pai e filho compartilham 
momentos quando Gabriel busca Santiago na escola, quando vão passear na avó, ou vão para casa onde brincam juntos, quando saem para a rua para tomar sol e andar de motoca. Na hora do banho e de dormir também acontecem momentos de interação pois, quando pode, Gabriel participa dessas atividades na rotina de Santiago. O pai aponta que outros momentos de interações ocorrem com a família estendida, em que ele, Vitória e Santiago costumam fazer programas com as famílias de origem de ambos. Relata, ainda, que o casal não costuma fazer programas sem a presença do filho e quando aconteceu, quem ficou com Santiago foi a avó materna. Contudo, são situações esporádicas, considerando que o casal está voltado para programas familiares nesse momento.

Gabriel relata sentir-se decepcionado por não poder passar mais tempo com seu filho, pois precisa se afastar constantemente devido às demandas de trabalho. Percebe que para ter um salário melhor precisa trabalhar mais, tanto que sua jornada de trabalho é dupla e ele entende que ela atrapalha em relação ao acompanhamento do crescimento de seu filho. Acredita que interfira também no exercício de sua paternidade, pois declara que "eu deixo a desejar como um pai, por não poder estar mais tempo presente. Durante a semana, a convivência é muito pouca, né. Então acredito que [...] isso acaba me tirando essa responsabilidade maior de pai. Com relação ao exercício da paternidade na contemporaneidade comparado ao modelo exercido por gerações anteriores, Gabriel ainda destaca "o princípio de ser pai é o mesmo" (sic), mas entende que as demandas contemporâneas interferem no modo de educar os filhos, pois considera que os valores estão diferentes, havendo maiores desafios na atualidade quando comparados ao período em que viveu sua infância e adolescência.

\section{Considerações finais}

A transição da conjugalidade para a parentalidade pode ser considerada um fenômeno complexo por envolver transformações significativas no funcionamento de todo o sistema familiar. Transformações essas que impactam os indivíduos e influenciam as interações estabelecidas entre os membros da família, que passam a construir uma nova dinâmica em suas relações. Além disso, uma grande parte dos casais enfrentam uma severa crise após o nascimento do primeiro filho, podendo ser considerada a primeira grande crise enfrentada no contexto familiar (CARTER; MCGOLDRICK, 1995).

Os participantes do presente estudo apresentaram uma perspectiva positiva com relação a sua experiência no processo de transição da conjugalidade para a parentalidade. Eles 
avaliam que o casal apresenta maior proximidade e cumplicidade nessa etapa, e tem conseguido lidar com as novas demandas e com a adoção dos papéis parentais, que envolvem diferentes atribuições e responsabilidades. Contudo, revelou-se também a ocorrência de situações-problema na vida desses casais, que são resolvidas de modo que a qualidade do sistema conjugal e seu ajustamento são mantidos. Pode-se entender que, mesmo com as adversidades que envolvem essa etapa do ciclo de vida da família, esses pais percebem que o casal tem conseguido lançar mão de recursos para manter a continuidade do sistema familiar.

Esses homens também convergem na percepção que diz respeito ao tempo destinado para o investimento conjugal, uma vez que, após o nascimento de seu filho, em todos os casos, o casal passou a voltar-se predominantemente às atividades familiares. Os momentos destinados ao casal acontecem, estritamente, quando seus filhos estão dormindo. A partir das entrevistas entendeu-se que esse desinvestimento da conjugalidade deve-se à falta de tempo que, no entendimento desses homens, está relacionado ao envolvimento com o filho, considerando a etapa em que se encontram. Ainda, em todos os casos, os casais não deixam os filhos aos cuidados de outras pessoas, sendo essa, na opinião dos pais, uma das razões para a ausência de programas conjugais.

Outro aspecto convergente entre os casos investigados refere-se à percepção da interferência da atividade laboral no exercício de sua paternidade. Em todos os casos, esse foi um dado destacado pelos participantes, os quais relataram lamentar por não estar presente por mais tempo na vida de seus filhos, para acompanhar o seu crescimento e desenvolvimento. Entretanto, os três participantes demonstraram perceber o trabalho como um importante fator para oferecer bem-estar e melhores recursos materiais às suas famílias.

Quanto aos aspectos divergentes, destacam-se os novos hábitos presentes na cultura ocidental contemporânea, que possibilita aos homens exercer a paternidade com maior envolvimento no que diz respeito à expressão de afeto e aos cuidados prestados aos seus filhos. Apenas no caso 1 observou-se maior disponibilidade do pai para com o seu filho nos momentos em que passam juntos, no que diz respeito aos cuidados prestados e envolvimento emocional. O modo de ser pai na contemporaneidade tem apresentado novas possibilidades de atuação, que são motivados pelas transformações ocorridas na atual sociedade. Isso diferencia o exercício da parentalidade atual do modelo exercido nas gerações passadas, implicando nos valores, hábitos e costumes da cultura ocidental contemporânea (ARRUDA; LIMA, 2013; HINTZ, 2001; NEGREIROS; FÉRES-CARNEIRO, 2004). Os pais descritos nos casos 2 e 3 também demonstraram em seus relatos envolverem-se com o cuidado de seus filhos, mas revelaram exercer um modelo de paternidade mais tradicional, enquanto que o pai descrito no 
caso 1 parece se diferenciar desse modelo, adaptando-se às demandas exigidas pela sociedade contemporânea no que diz respeito aos papeis parentais.

Além disso, foram encontradas divergências com relação à divisão das tarefas domésticas. Nos casos 2 e 3, destaca-se assimetria quanto a essa divisão, pois parece que as mulheres que se encarregam dessas atividades. No entanto, Gabriel (caso 3) refere que houve uma combinação do casal para divisão de tarefas, considerando o tempo disponível de cada um em casa. Já no caso 2, essa combinação parece ter se dado tacitamente, visto que não houve uma contratação explícita dessas atribuições. Ao comparar essas informações com o caso 1, observou-se que Pedro adota uma postura diferenciada de Guilherme e de Gabriel, já que demonstra maior envolvimento nas tarefas domésticas, o que evidencia, mais uma vez, sua proximidade ao exercício contemporâneo de paternidade exigido pela sociedade atual.

A partir da análise desses três casos foi possível refletir acerca do processo de transição para a parentalidade na perspectiva paterna, em que foi evidenciado não só a existência de transformações e conflitivas na relação conjugal nessa etapa do ciclo de vida da família, mas também uma dinâmica funcional para lidar com essas situações na percepção desses homens. Acredita-se que a existência desses recursos se devam à relação estabelecida entre eles e suas esposas antes do nascimento do bebê, na qual se fez presente um envolvimento emocional, consistindo em um fator preditor da manutenção do sistema familiar (MENEZES; LOPES, 2007). Além disso, observou-se que, mesmo com as mudanças contemporâneas, o modelo tradicional ainda se faz presente na constituição da paternidade desses homens, em que, dois dos três casos analisados, apresentaram as características desse modelo nas interações com sua família, não só no que diz respeito à expressão de afeto e interação com os filhos; mas também, às tarefas parentais e domésticas, repercutindo no papel desempenhado pelo homem nessas famílias.

$\mathrm{Na}$ perspectiva desses homens, tornar-se pai e constituir a sua paternidade pode ser traduzido em um processo que proporciona satisfação e felicidade, havendo ainda um sentimento de completude, motivado pela constituição de sua família. Os resultados encontrados, considerando o método deste estudo, por certo não podem ser generalizáveis. Deste modo, sugere-se a ampliação do estudo da temática, a partir de novas pesquisas, de diferentes métodos e delineamentos, a fim de contribuir para a compreensão das vicissitudes da paternidade atual. 


\title{
TRANSITIONS IN THE LIFE FAMILY CYCLE: THE FATHER PERSPECTIVE OF THE TRANSITION TO PARENTING PROCESS
}

\begin{abstract}
The paternity building process is a complex phenomenon, considering, in particular, the transition from the conjugality to parenthood. In this sense, this study investigated the fathers perception about the changes will be shown in relation to marital and construction of parenthood. A qualitative research study of multiple cases was conducted with three men, residents of the Porto Alegre area, married and common-law marriage with children up to one year and six months. Data analysis was based on multiple case study in the systemic perspective of the family. The participants showed a positive outlook regarding their experience at this period of life, having deal with the new demands and adoption of parental roles that involve different duties and responsibilities. However, it is also showed problem situations in these couples, who are resolved so that the quality of the marital system and its adjustment are maintained. The results highlight the relevance of emotional closeness and intimaty established by the couple before the child's birth as a predictor for system maintenance that time the family life cycle.
\end{abstract}

Keywords: Parenting; Paternity; Family systems theory.

\section{TRANSACCIONES EN EL CICLO DE VIDA FAMILIAR: PERSPECTIVA PATERNA FRENTE AL PROCEDIMIENTO DE TRANSICIÓN PARA PARENTALIDAD}

\begin{abstract}
Resumen
El proceso de construcción de la paternidad es un fenómeno complejo, teniendo en cuenta, en particular, la transición de civil a la paternidad. En este sentido, el presente estudio investigó la percepción de los padres sobre los cambios se muestran en relación con el matrimonio y la construcción de la paternidad. Un estudio de investigación cualitativa de múltiples casos se llevó a cabo con tres hombres, los residentes del Gran Porto Alegre, casado y unión de hecho con hijos de hasta un año y seis meses. Análisis de los datos se basó en el estudio de casos múltiples a la luz de la perspectiva sistémica de la familia. Los participantes presentaron una actitud positiva respecto a su experiencia en esta etapa de la vida, después de haber logrado hacer frente a las nuevas demandas y adopción de roles parentales que implican diferentes funciones y responsabilidades. Sin embargo, también se revela situaciones problemáticas en la vida de estas parejas, que se resuelven de manera que la calidad del sistema civil y su ajuste se mantienen. Los resultados refuerzan la importancia de la cercanía emocional e intimidad establecido por la pareja antes del nacimiento del niño como un predictor para el mantenimiento del sistema que el tiempo del ciclo de vida familiar.
\end{abstract}

Palabras clave: Educación de los hijos; Paternidad; Teoría de los sistemas familiares. 


\section{Referências}

ANDOLFI, Maurizio; A família como sistema de interação. In: A terapia familiar: um enfoque interacional. São Paulo: Workshopsy, 1996.

ARRUDA, S.L.S.; LIMA, M.C.F. O novo lugar do pai como cuidador da criança. Estudos Interdisciplinares em Psicologia, Londrina, v. 4, n. 2, p. 201- 216, dez. 2013.

BLEGER, José. Psico-higiene e psicologia institucional. Porto Alegre: Artmed, 1984.

BRADT, Jack O. Tornando-se pais: famílias com filhos pequenos. In: As mudanças no ciclo de vida familiar: uma estrutura para a terapia familiar. 2. ed. Porto Alegre: Artmed, 1995, p. 207- 222.

BRASIL. Lei de Diretrizes e Bases da Educação Nacional - Lei no 9.394/96, de 20 de dezembro de 1996. Diário Oficial da União, Brasília, DF, 23 dez. 1996.

CARTER, B.; MCGOLDRICK, M. As mudanças no ciclo de vida familiar: uma estrutura para a terapia familiar. In: As mudanças no ciclo de vida familiar: uma estrutura para a terapia familiar. 2. ed. Porto Alegre: Artmed, 1995, p. 7- 29.

DIAS, A.C.G.; LOPES, R.C.S. Representações de maternidade de mães jovens e suas mães. Psicologia em Estudo, Maringá, v. 8, n. esp., p. 63-73, 2003.

FÉRES-CARNEIRO, Terezinha (org). Família e casal: efeitos da contemporaneidade. Rio de Janeiro: PUC-RIO editora, 2009, 320 p.

FREITAS, W.M.F.; COELHO, E.A.C.; SILVA, A. Sentir-se pai: a vivência masculina sob o olhar de gênero. Caderno de Saúde Pública. Rio de Janeiro, v. 23, n. 1, p. 137- 145, 2007.

GOMES, A.; RESENDE, V.R. O pai presente: o desvelar da paternidade em uma família contemporânea. Psicologia: Teoria e Pesquisa. Brasília, v. 20, n. 2, p. 119-125, 2004.

HERNANDEZ, J.A.E.; HUTZ, C.S. Transição para a parentalidade: ajustamento conjugal e emocional. PSICO, Porto Alegre, v. 40, n. 4, p. 414-421, 2009.

HINTZ, H.C.; BAGINSKI, P.H. Vínculo conjugal e transição para a parentalidade: fragilidades e possíveis superações. Revista Brasileira de Terapia Família, n. 4, v. 1, p. 1022, 2012.

HINTZ, Helena Centeno. Novos tempos, novas famílias? Da modernidade à pósmodernidade. Pensando Famílias, v. 3, n. 1, p. 8-19, 2001.

JABLONSKI, Bernardo. A divisão de tarefas domésticas entre homens e mulheres no cotidiano do casamento. Psicologia, Ciência e Profissão, v. 30, n. 2, p. 262- 275. 2010.

MAGAGNIN, Cirilo; KÖRBES, Jussara Maria; HERNANDEZ, José Augusto E.; CAFRUNI, Sirlei; TAILOR Rodrigues, Manoel; ZARPELON, Marlei. Da conjugalidade à parentalidade: gravidez, ajustamento e satisfação conjugal. Aletheia. Canoas, n. 17-18, p. 41-52, 2003. 
MARTINS, C.A.; ABREU, W.J.C.P.; FIGUEIREDO, M.C.A.B. Tornar-se pai e mãe: um papel socialmente construído. Revista de enfermagem, v. 4, n. 2, p. 121-131, 2014.

MENEZES, C.C.; LOPES, R.C.S.L. Relação Conjugal na transição para a parentalidade: gestação até dezoito meses do bebê. Psico-USF, Itatiba, v. 12, n. 1, p. 89-93, 2007.

MINUCHIN, Salvador. Famílias: funcionamento e tratamento. Porto Alegre: Artes Médicas, 1982.

NEGREIROS, T.C.G.M.; FÉRES-CARNEIRO, T. Masculino e feminino na família contemporânea. Estudo em Psicologia, Rio de Janeiro, v. 4, n. 1, p. 34-47, 2004.

NICHOLS, M.P.; SCHWARTZ, R.C. Terapia familiar: conceitos e métodos. 7. ed. Porto Alegre: Artmed, 2007.

OSORIO, Luiz Carlos. Família hoje. Porto Alegre: Artmed, 1996.

PICCININI, C.A.; GOMES, A.G.; DE NARDI, T.; LOPES, R.S. Gestação e a constituição da maternidade. Psicologia em Estudo, Maringá, v. 13, n. 1, p. 63-72, 2008.

SPANIER; Graham B. Measuring duadic ajustment: new scales for assessing the quality of marriage and similar dyads. Journal of marriage and the family. v. 38, n. 1, p. 15-28, 1976.

STAUDT, A.P.; WAGNER, A. Paternidade em tempos de mudança. Psicologia: Teoria e Prática. São Paulo, v. 10, n. 1, p. 174-185, 2008.

SUTTER, C.; BUCHER-MALUSCHKE, J.S.N.F. Pais que cuidam dos filhos: a vivência masculina na paternidade participativa. Psico, v. 39, n.1, p.74-82, 2008.

TOSIM, Ana Silvia. O psicodiagnóstico e as abordagens sistêmico-familiares. 2005. 61p. Monografia (Especialização em Terapia Familiar e de Casal) - Familiare Instituto Sistêmico, Florianópolis, 2005.

VASCONCELOS, Maria José Esteves. Pensamento sistêmico: o novo paradigma da ciência. Campinas, SP: Papirus, 2013, 10ed.

YIN, Robert K. Estudo de caso: planejamento e métodos. 2. ed. Porto Alegre: Bookman, 2015.

Data de recebimento: 13/01/2016

Data de aceite: 14/06/2017

\section{Sobre as autoras:}

Bruna Soares é Psicóloga pelas Faculdades Integradas de Taquara (FACCAT). Psicóloga clínica no Centro de Serviços em Psicologia (CESEP). É psicóloga parceira da Zelo Consultoria em Educação e Desenvolvimento Infantil. Além disso, é membro do Núcleo do Ensino Médio, do Laboratório de Orientação Profissional da FACCAT, o qual foi bolsista em seu último ano de formação. Possui experiência na área clínica e na área institucional. 
Endereço Eletrônico: bruna_soares1024@hotmail.com

Patrícia Manozzo Colossi é Doutora em Psicologia Clínica (Unisinos), Especialista em Terapia de Casais e Famílias (Unisinos), Professora da graduação em psicologia das Faculdades Integradas de Taquara(FACCAT), supervisora clínica no Centro de Serviços em Psicologia (Cesep/FACCAT) e psicóloga clínica de adultos, casais e famílias na clínica particular. Endereço Eletrônico: patriciacolossi@faccat.br / pmcolossi@gmail.com 